\title{
A teoria de Kant do a priori à luz da Biologia Contemporânea (1941)
}

\author{
LORENZ, K. Kant's Doctrine of the A Priori in The Light of \\ Contemporary Biology. In: RUSE, M. (Org.). Philosophy AfterDarwin: \\ Classic and Contemporary Readings. [S.I.]: Princeton University \\ Press, 2009, p. 231-247.
}

\author{
Henrique Capeleiro Maia (Tradutor) \\ Orcid: https://orcid.org/0000-0003-3291-6307 - E-mail:henrique.maia@ufpe.br
}

Para Kant, as formas do espaço, tempo, causalidade e demais categorias do nosso pensamento são dados estabelecidos a priori, determinando a forma de toda a nossa experiência, e, de fato, tornando a experiência possível. Para Kant, a validade destes princípios primários da razão é absoluta. Esta validade é fundamentalmente independente das leis da natureza real que está por detrás das aparências. Esta validade não é para ser pensada como surgindo destas leis. As categorias e formas da intuição a priori não podem estar relacionadas com as leis inerentes na 'coisa-em-si', seja por abstração ou por quaisquer outros meios. A única coisa que podemos afirmar sobre a 'coisa-em-si', de acordo com Kant, é a realidade da sua existência. A relação que existe entre ela e a forma na qual esta afeta os nossos sentidos e aparece no nosso mundo de experiência é, para Kant, alógica (para exagerar um pouco). Para Kant, a coisa-em-si é, em princípio, não passível de ser conhecida, porque a forma da sua aparência é determinada pelas formas e categorias puramente ideais da intuição, de modo que a sua aparência não tem conexão com a sua essência. Este é o ponto de vista do idealismo 'transcendental', ou 'crítico', reafirmado numa forma condensada.

A orientação de Kant foi transformada muito liberalmente por vários filósofos naturais. Em particular, os cada vez mais urgentes questionamentos da teoria da evolução levaram a

\footnotetext{
' LORENZ, K. Kant's Lehre vom Apriorischen im Lichte gegenwärtiger Biologie. Blätter für Deutsche Philosophie, 1941. A presente tradução foi feita a partir da versão inglesa (Kant's Doctrine of the A Priori in The Light of Contemporary Biology), cotejada com o original sempre que necessário.
} 
concepções do a priori que não estão talvez assim tão afastadas das do próprio Kant como das do filósofo kantiano preso aos termos exatos da definição [que] Kant [dá] dos seus conceitos.

O biólogo, convencido do fato dos grandes eventos criativos da evolução, coloca a Kant estas questões: [1] Não é a razão humana, com todas as suas categorias e formas de intuição, algo que evoluiu organicamente numa relação contínua de causa-efeito com as leis da natureza imediata, assim como o cérebro humano? [2] Não seriam estas leis da razão necessárias para o pensamento a priori completamente diferentes se não tivessem sido sujeitas a um modo histórico de origem inteiramente diferente, e se, consequentemente, nós tivéssemos sido dotados de um sistema nervoso central completamente diferente? [3] É de todo provável que as leis do nosso aparato cognitivo possam estar desconectadas das do mundo externo? [4] Pode um órgão, que evoluiu num processo de lidar continuamente com as leis da natureza, ter permanecido tão sem influência que a teoria das aparências possa ser explorada independentemente da existência da coisa-em-si, como se as duas fossem totalmente independentes uma da outra? Ao responder estas questões, o biólogo adota um ponto de vista marcadamente circunscrito. A exposição deste ponto de vista é o assunto deste presente artigo. Não estamos só interessados nas discussões especiais sobre o espaço, tempo e causalidade. As últimas são, para o nosso estudo, apenas exemplos da teoria kantiana do a priori, e são tratadas incidentalmente em nossa comparação com as visões do a priori tomadas pelo idealismo transcendental e pelo biólogo.

É dever do cientista natural tentar uma explicação natural antes de se contentar com o recorrer a fatores externos à natureza. Este é um dever importante do psicólogo que tenha de lidar com o fato de que algo como as formas de pensamento a priori de Kant realmente existam. Alguém que esteja familiarizado com os modos de reação inatos dos organismos sub-humanos pode prontamente colocar em hipótese que o a priori se deve às diferenciações hereditárias do sistema nervoso central que se tornou característico da espécie, produzindo disposições hereditárias para pensar em certas formas. Tem de se perceber que esta concepção do 'a priori' como um órgão significa a destruição do conceito: algo que evoluiu numa adaptação evolutiva às leis do mundo natural externo, evoluiu a posteriori num certo sentido, mesmo se de uma forma totalmente diferente da abstração ou dedução a partir da experiência prévia. As semelhanças funcionais que levaram muitos pesquisadores a visões lamarckianas sobre a origem dos modos de reação hereditários a partir de uma anterior 'experiência da espécie' são hoje reconhecidas como completamente enganadoras.

O caráter essencial das ciências naturais de hoje significa um tal abandono tão significativo do idealismo transcendental que uma fratura se abriu entre o cientista e o filósofo kantiano. A fratura é causada por uma mudança fundamental dos conceitos da coisa-em-si e do transcendental, uma mudança que resulta da redefinição do conceito do a priori. Se o aparato 'a priori' da experiência possível com todas as suas formas da intuição e categorias não é algo imutavelmente determinado por fatores estranhos à natureza, mas, ao invés, algo que espelha as leis naturais em contato com as quais evolui na mais estreita interação recíproca, então a fronteira dos transcendente perde a sua base sólida. Muitos aspetos da coisa-em-si que escapam completamente a serem experimentados pelo nosso aparato cotidiano do pensamento e percepção podem encontrar-se dentro dos limites da experiência possível num futuro próximo, geologicamente falando. Muitos desses aspetos que hoje estão dentro da esfera do imanente podem ter estado para lá desses limites no passado recente da humanidade. É óbvio que a questão de até onde o absolutamente existente pode ser experimentado por um determinado ser a partir da infinita abundância de organismos vivos não pode, é claro, ter a mínima influência em sua essência fundamental. 
Contudo, essa consideração altera algo na definição que temos de fazer da coisa-em-si para lá dos fenômenos. Para Kant, (que em todas as suas especulações apenas tomou em consideração o homem maduro civilizado, representando um sistema imutável criado por Deus) nenhum obstáculo se apresentou para definir a coisa-em-si como fundamentalmente incognoscível. Na sua forma estática de a olhar, ele podia incluir o limite da experiência possível na definição da coisa-em-si. Este limite seria o mesmo para o homem e para a ameba - infinitamente longe da coisa-em-si. Perante a visão do indubitável fato da evolução, isto não mais é sustentável. Mesmo que reconheçamos que o absolutamente existente nunca pode ser conhecido (mesmo para os mais altos seres imagináveis haverá um limite determinado pela necessidade das formas categóricas do pensamento), o limite separando o experimentável do transcendental tem de variar para cada tipo de organismo. A localização do limite tem de ser investigada separadamente para cada tipo de organismo. Significaria um antropomorfismo injustificável incluir a atual localização puramente acidental deste limite para a espécie humana na definição da coisa-em-si. Se, apesar da indubitável modificabilidade evolutiva do nosso aparato de experiência, se quisesse, contudo, continuar a definir a coisa-em-si como aquilo que é incognoscível para este aparato, a definição do absoluto teria de, por isso, ser tida como relativa, [o que é] obviamente um absurdo. Pelo contrário, toda a ciência natural precisa urgentemente de um conceito do absolutamente real que seja tão pouco antropomórfico e tão independente quando possa da localização acidental atual dos limites daquilo que é humanamente experimentável. O absolutamente atual não pode de todo ser uma questão do grau pelo qual se reflete no cérebro humano, ou qualquer outra forma temporária. Por outro lado, é objeto de um ramo muito importante da pesquisa natural comparada examinar a natureza dessa reflexão e investigar se ela assume a forma de símbolos flagrantemente simplistas e apenas superficialmente análogos ou até que ponto ela fornece detalhes e até aonde vai a sua precisão. Por esta investigação das formas pré-humanas de conhecimento, esperamos obter pistas quanto ao modo de funcionar e origem histórica do nosso próprio conhecimento, e, desta forma, levar adiante a crítica do conhecimento mais além do que seria possível sem tais comparações.

Eu afirmo que quase todos os cientistas naturais de hoje, pelo menos todos os biólogos, consciente ou inconscientemente assumem no seu trabalho diário uma verdadeira relação entre a coisa-em-si e o fenômeno da nossa experiência subjetiva, mas uma relação que não é de todo 'puramente' ideal no sentido kantiano. Chego mesmo afirmar que o próprio Kant assumiu isto em todos os resultados da sua própria pesquisa empírica. Na nossa opinião, a verdadeira relação entre a coisa-em-si e a forma específica da sua aparência a priori foi determinada pelo fato de que a forma da aparência se desenvolveu como uma adaptação às leis da coisa-em-si no confronto do lidar com estas leis continuamente presentes durante a história evolutiva da humanidade, durando centenas de milênios. Esta adaptação forneceu ao nosso pensamento uma estrutura inata que corresponde, num grau considerável, à realidade do mundo externo. 'Adaptação' é uma palavra que está já carregada com significado e [que pode ser] facilmente incompreendida. Não deve denotar, na condição presente, mais do que o'corresponder' das nossas formas e categorias da intuição àquilo que realmente existe da [mesma] maneira em que o nosso pé corresponde ao chão ou a barbatana do peixe à água. $\mathrm{O}$ a priori que determina as formas da aparência das coisas reais do nosso mundo é, em suma, um órgão, ou, mais precisamente, o funcionamento de um órgão. Ficamos mais próximos de compreender o a priori se o confrontarmos com as questões colocadas a tudo o que é orgânico: [a] 'Para quê', [b] 'de onde' e [c] 'porquê'. Estas questões são, primeiramente, [a] como é que garante a preservação a espécie; segundo, [b] qual é a sua origem genealógica; terceiro, [c] que causas naturais o tornam possível? Nós estamos convencidos que o a priori se baseia em sistemas nervosos centrais que 
são tão reais como as coisas do mundo externo, cuja forma fenomenal determinam. Este aparato nervoso central não mais prescreve leis da natureza do que o casco do cavalo prescreve a forma do chão. Tal como o casco do cavalo, este aparato nervoso central tropeça em mudanças não previstas em sua tarefa. Mas tal como o casco do cavalo está adaptado ao chão da estepe com o qual tem de lidar, também o nosso aparato nervoso central [que serve] para organizar a imagem do mundo está adaptado ao mundo real com o qual o homem tem de lidar. Tal como qualquer órgão, este aparato alcançou a sua forma preservadora-da-espécie através deste lidar do real com o real durante a sua evolução genealógica, que dura há muitos éons.

A nossa visão da origem do 'a priori' (uma origem que, num certo sentido, é 'a posteriori') responde muito apropriadamente à questão de Kant sobre se as formas da percepção do espaço e do tempo, que não derivamos da experiência, (como Kant, contrariamente a Hume, enfatiza muito corretamente), mas que são a priori nas nossas representações, "não eram meras quimeras do cérebro feitas por nós às quais nenhum objeto corresponde, pelo menos não [corresponde] adequadamente" ${ }^{\prime 2}$. Se concebermos o nosso intelecto como a função de um órgão (e aqui não existe qualquer argumento válido contra isto), a nossa resposta óbvia à questão do por que a forma da sua função está adaptada ao mundo real é a seguinte: As nossas categorias e formas da percepção, fixadas anteriormente à experiência individual, estão adaptadas ao mundo externo pelas mesmas razões que o casco do cavalo já está adaptado ao chão da estepe antes do cavalo ter nascido e a barbatana do peixe está adaptada à água antes do peixe ser desovado. Nenhuma pessoa razoável acredita que em qualquer destes casos a forma do órgão 'prescreve' as suas propriedades ao objeto. É para todos autoevidente que a água possui as suas propriedades independentemente de se as barbatanas do peixe estão biologicamente adaptadas ou não a essas propriedades. Muito evidentemente, algumas propriedades da coisa-em-si, que estão no fundo do fenômeno 'água', levaram à forma específica de adaptação das barbatanas, que evoluíram, independentemente umas das outras, em peixes, répteis, pássaros, mamíferos, cefalópodes, caracóis, lagostins, minhocas, etc. Foram obviamente as propriedades da água que prescreveram a estes diferentes organismos a forma e função correspondentes do seu órgão de locomoção. Mas ao considerar a estrutura e modo de função do seu próprio cérebro, o filós ofo transcendental assume algo fundamentalmente diferente. No parágrafo 11 dos Prolegômenos, Kant diz: "Se alguém tivesse a mínima dúvida que ambas (as formas da intuição do espaço e tempo) não são determinações da coisa-em-si, mas meras determinações da sua relação com a sensibilidade, eu gostaria de saber como se poderia saber a priori, e, como tal, antes de toda a familiarização com as coisas, nomeadamente antes delas nos terem sido dadas, como deveria ser a sua intuição, como é aqui o caso com o espaço e tempo". Esta questão clarifica dois fatos muito importantes. Primeiro, mostra que Kant, não mais que Hume, pensou a possibilidade de uma adaptação formal entre pensamento e realidade de outra forma que não pela abstração da experiência anterior. Segundo, mostra que ele assumiu a impossibilidade de qualquer forma diferente de origem. Além do mais, mostra a grande e fundamentalmente nova descoberta de Kant, i.e., que o pensamento e percepção humanas têm certas estruturas que antecedem toda a experiência individual.

O mais certo é que Hume estivesse errado quando queria derivar tudo o que é a priori daquilo que os sentidos fornecem à experiência, tal como errado [também] estava Wundt ${ }^{3}$ ou Helmholtz ${ }^{4}$, que simplesmente explicaram [tudo o que há a priori] como uma abstração da expe-

\footnotetext{
2 Prolegômenos, Primeira Parte, nota III.

${ }^{3}$ N. do T.: Wilhelm Maximilian Wundt (1832-1920), que, com William James (1842-1910), é considerado um dos pais da psicologia moderna.

${ }^{4}$ N. do T.: Hermann Ludwig Ferdinand von Helmholtz (1821-1894), médico e físico alemão que publicou trabalhos em psicologia.
} 
riência precedente. A adaptação do a priori ao mundo real não mais se originou a partir da 'experiência' do que a adaptação da barbatana do peixe às propriedades da água. Tal como a forma da barbatana é dada a priori, anteriormente a qualquer lidar individualmente com a água por parte dos pequenos peixes, e tal como é esta forma que torna possível este poder lidar, assim é também o caso com as nossas formas da percepção e categorias na sua relação com o nosso lidar com mundo externo através da experiência. Para os animais, existem limitações específicas às formas da experiência que são possíveis. Acreditamos que podemos demonstrar a mais estreita e provável relação genética entre os a priori destes animais e o nosso a priori humano.

Contrariamente a Hume, acreditamos, como o fez Kant, na possibilidade de uma ciência 'pura' das formas inatas do pensamento humano independente de toda a experiência. Esta ciência 'pura', contudo, apenas poderia fornecer um entendimento muito unilateral da essência das formas de pensamento a priori, porque negligência a natureza orgânica destas estruturas e não coloca a questão biológica básica que se refere ao significado preservador-da-espécie. Falando sem rodeios, é como se alguém quisesse escrever uma teoria 'pura' das características de uma câmara fotográfica moderna, uma Leica, por exemplo, sem levar em consideração que isto é um aparato para fotografar o mundo externo, e sem consultar as fotografias que a câmara produz que permitem que se compreenda a sua função e o sentido essencial da sua existência. No que se refere às fotografias produzidas (tal como as experiências), a Leica é inteiramente $a$ priori. Existe antes de e independentemente de todas as fotografias; na verdade, determina de antemão a forma das imagens, tornando estas, pois, em primeiro lugar possíveis. Agora eu afirmo: separar a 'Leicologia pura' da teoria das fotografias que ela produz tem tão pouco sentido quanto separar a teoria do a priori da teoria do mundo externo, a fenomenologia da teoria da coisa-em-si. Todas as leis do nosso intelecto que nele encontramos a priori não são aberrações da natureza. Nós [sobre]vivemos por conta delas! Tal como não se podia originar a Leica sem a atividade da fotografia, levada a cabo muito antes da Leica ter sido construída, tal como a Leica pronta com todos os seus incrivelmente bem concebidos e 'correspondentes' detalhes não caiu dos céus, também tal não aconteceu com a nossa infinitamente mais maravilhosa 'razão pura'. Ela, também, chegou à sua relativa perfeição a partir da sua atividade, do seu acordo com a coisa-em-si.

Embora para o idealista transcendental a relação entre a coisa-em-si e a sua aparência seja estranha à natureza e alógica, é inteiramente real para nós. É certo que não apenas a coisa-em-si 'afeta' os nossos receptores, como também vice-versa, os nossos efetuadores ${ }^{5}$, por sua parte, 'afetam' a realidade absoluta. A palavra 'atualidade' vem do verbo 'atuar' (Wirklichkeit kommt von Wirken ${ }^{6}$ !). O que aparece no nosso mundo não é de todo apenas a nossa experiência influenciada unilateralmente pelas coisas externas reais como estas operam sobre nós através das lentes das possibilidades ideais da experiência. O que testemunhamos como experiência é sempre um lidar com o real e nós com o real fora de nós. Assim, a relação entre os eventos dentro e fora de nós não é alógica e basicamente não proíbe que se tirem conclusões sobre as leis do mundo externo a partir das leis dos eventos internos. Pelo contrário, esta relação é uma que existe entre imagem e objeto, entre um modelo simplificado e a coisa real. É a relação de uma analogia de maior ou menor distanciamento. O grau desta analogia está fundamentalmente aberto à pesquisa comparativa. Isto é, é possível fazer afirmações sobre se a concordância entre aparência e atualidade é mais ou menos exata ao se comparar um humano com outro, ou um organismo vivo com outro.

\footnotetext{
${ }^{5}$ N. do T.: O contraponto fisiológico de receptor: aquilo que em nós é responsável por iniciar uma ação.

6 N. do T.: Realidade vem de ação.
} 
Destas premissas também depende o fato autoevidente de que há mais ou menos julgamentos corretos sobre o mundo externo. A relação entre o mundo dos fenômenos e a coisa-em-si não está, pois, fixada para todo o sempre por leis ideais da forma que são estranhas à natureza e, em princípio, inacessíveis à investigação. Nem os julgamentos feitos com base nestas 'necessidades de pensamento' têm uma validade independente e absoluta. Ao invés, todas as nossas formas de intuição e categorias são completamente naturais. Tal como todos os outros órgãos, eles são receptáculos evolutivamente desenvolvidos para a recepção e utilização retroativa destas consequências válidas da coisa-em-si, com a qual nós temos de lidar se quisermos permanecer vivos e preservar a nossa espécie. A forma especial destes receptáculos orgânicos tem propriedades da coisa-em-si numa relação desenvolvida completamente a partir de conexões naturais reais. Os receptáculos orgânicos estão adaptados a estas propriedades duma forma que tem uma suficiência biológica prática, mas que não é, de forma alguma, absoluta nem mesmo tão precisa que alguém pudesse dizer que a sua forma corresponde à da coisa-em-si. Mesmo se nós, os cientistas naturais, somos, num certo sentido, realistas ingênuos, nós ainda assim não tomamos a aparência pela coisa-em-si nem a realidade experimentada pelo absolutamente existente. Como tal, nós não ficamos surpreendidos por encontrar as leis da 'razão pura' emaranhadas nas mais sérias contradições, não apenas umas com as outras, mas também com os fatos empíricos sempre que a pesquisa demanda maior precisão. Isto acontece particularmente onde a física e a química entram na fase nuclear. Aí, não apenas a forma-intuição da percepção-espaço se quebra, como também as categorias da causalidade ou a da substancialidade, e, num certo sentido, até a da quantidade (embora a quantidade, pelo contrário, aparente ter a validade mais incondicional, exceto para a forma-intuição da percepção-tempo). 'Necessária para o pensamento' de forma alguma significa 'absolutamente válida' perante estes fatos empíricos, altamente essenciais na física nuclear, mecânica quântica e teoria das ondas.

O fato de nos apercebermos de que todas as leis da 'razão pura' são baseadas em estruturas altamente físicas ou mecânicas do sistema nervoso central humano, que se desenvolveu ao longo de muitos éons como qualquer órgão, por um lado abala a nossa confiança nas leis da razão pura e, por outro, eleva substancialmente a nossa confiança nelas. A afirmação de Kant que as leis da razão pura têm validade absoluta, que pois todo o ser racional imaginável, mesmo se fosse um anjo, teria de obedecer às mesmas leis do pensamento, mostra-se uma presunção antropocêntrica. Por certo o 'teclado' fornecido pelas formas da intuição e categorias - o próprio Kant assim as chama - é algo que decididamente reside no lado psico-estrutural da unidade psicofísica do organismo humano. As formas da intuição e categorias relacionam-se com a 'liberdade' da mente (se é que existe tal coisa) assim como as estruturas físicas estão normalmente relacionadas aos possíveis graus de liberdade do psíquico, nomeadamente quer a apoiar quer a restringir ao mesmo tempo. Mas certamente estas caixas categóricas desajeitadas nas quais temos de empacotar o nosso mundo externo "por forma a poder detalhá-las como experiências" (KANT) não podem reivindicar qualquer autonomia e validade absoluta. Isto se torna claro no momento em que as concebemos como adaptações evolutivas - e eu realmente gostaria de saber que argumento científico poderia ser levantado contra esta concepção. Ao mesmo tempo, contudo, a natureza da sua adaptação mostra que as formas da intuição e as categorias deram provas de si enquanto hipóteses de trabalho na lida da nossa espécie com a realidade absoluta do ambiente (apesar da sua validade como sendo apenas aproximadas e relativas). Isto é clarificado pelo fato paradoxal de que as leis da 'razão pura', que quebram a cada passo da ciência teórica moderna, no entanto resistiram (e ainda resistem) ao teste da luta pela preservação das espécies. 
Os 'pontos' produzidos pelos 'ecrãs' grosseiros usados nas reproduções de fotografias em nossos jornais diários são representações satisfatórias quando olhadas superficialmente, mas não resistem à inspeção mais ampliada de uma lupa. Da mesma forma, as reproduções do mundo pelas nossas formas de intuição e categorias quebram logo que delas se exija uma representação mais apurada dos seus objetos, tal como é o caso da mecânica das ondas e da física nuclear. Todo o conhecimento que um indivíduo pode sacar da realidade empírica da 'imagem-mundo física' é essencialmente apenas uma hipótese de trabalho. E no que diz respeito às funções preservadoras-da-espécie, todas aquelas estruturas inatas da mente às quais chamamos 'a priori' são, de igual modo, apenas hipóteses de trabalho. Nada é absoluto exceto aquilo que se esconde nos, e por detrás dos, fenômenos. Nada que o nosso cérebro possa pensar tem absoluta validade a priori no verdadeiro sentido da palavra, nem mesmo a matemática com todas as suas leis. As leis da matemática apenas são um órgão para a quantificação das coisas externas e, mais do que isso, um órgão extremamente importante para a vida do homem, sem o qual ele nunca poderia ter desempenhado o seu papel em dominar a terra, e que, como tal, deu amplas provas da perspectiva biológica, assim como todas as outras estruturas 'necessárias' do pensamento. Claro que a matemática 'pura' não é apenas possível, é, como teoria das leis internas deste miraculoso órgão de quantificação, de uma importância que dificilmente pode ser sobrestimada. Mas isto não nos justifica em torná-lo absoluto. $\mathrm{O}$ ato de contar e os números matemáticos afetam a realidade quase da mesma forma que uma draga com as suas pás. Considerando estatisticamente, num grande número de casos individuais, cada pá ergue aproximadamente a mesma quantidade, mas, na verdade, nunca podem duas ter o mesmo conteúdo. A equação matemática pura é uma tautologia: eu afirmo que se a minha draga puxa um tal número de pás, então tal número de pás são puxadas. Duas pás da minha máquina são absolutamente iguais uma à outra porque, estritamente falando, é a mesma pá de cada vez, nomeadamente o número um. Mas apenas a frase vazia tem sempre esta validade. Duas pás cheias com isto ou aquilo nunca são iguais uma à outra, o número um sendo aplicado a um objeto real nunca encontrará o seu igual em todo o universo. É verdade que dois mais dois é igual a quatro, mas duas maçãs, carneiros, ou átomos mais dois nunca iguala outros quatro, porque não existem maçãs, carneiros ou átomos iguais. Neste sentido, chegamos ao fato paradoxal que a equação dois mais dois é igual a quatro na sua aplicação a unidades reais, tais como maçãs ou átomos, tem um grau muito menor de aproximação à realidade do que a equação dois milhões mais dois milhões é igual a quatro milhões, porque as dissimilaridades das unidades contadas se nivelam estatisticamente no caso de um grande número. Considerada como uma hipótese de trabalho ou como um órgão funcional, a forma do pensamento de uma quantificação numérica é, e permanece, um dos mais miraculosos aparatos que a natureza alguma vez criou; evoca a admiração do biólogo, particularmente pelo incrível âmbito de sua aplicação, mesmo que não consideremos absoluta a sua esfera de validade.

Seria inteiramente concebível imaginar um ser racional que não quantifica por meio de numeração matemática (que não usa 1, 2, 3, 4, 5, o número de indivíduos aproximadamente igual entre si, tal como carneiros, átomos ou marcas rodoviárias, para marcar a quantidade que tem à mão), mas que os capta imediatamente de outra forma qualquer. Ao invés de quantificar água pelo número de recipientes de litro preenchidos, poderia, por exemplo, concluir a partir da tensão de um balão de borracha de um determinado tamanho quanta água [o balão] contém. Pode muito bem ser pura coincidência, por outras palavras, produzido por causas puramente históricas, que o nosso cérebro calha ser capaz de quantificar mais prontamente quantidades extensas do que intensas. Não é de todo uma necessidade do pensamento e seria inteiramente concebível que a capacidade de quantificar intensamente, de acordo com o método 
indicado pelo exemplo de medir a tensão no balão de borracha, poderia se desenvolver até ao ponto onde se tornaria igualmente valiosa, substituindo a matemática numérica. De fato, a capacidade de estimar quantidades imediatamente, presente no homem e num certo número de animais, deve-se provavelmente a um tal processo intensivo de quantificação. Uma mente quantificando de uma forma puramente intensiva levaria a cabo algumas operações de forma mais simples e imediata do que a nossa matemática do tipo da 'draga'. Por exemplo, poderia conseguir calcular curvas imediatamente, o que apenas é possível na nossa matemática extensiva por meio de um desvio do cálculo integral e diferencial, um desvio que nos arrasta por sobre as limitações dos passos numéricos, mas que ainda a eles se prende conceptualmente. Um intelecto quantificando puramente por intensidade não seria capaz de apreender que dois mais dois é igual a quatro. Como não teria qualquer entendimento para o número um, a nossa caixa vazia numérica, também não compreenderia o nosso postulado da igualdade de duas tais caixas e responderia ao nosso arranjar de uma equação que esta estaria incorreta, porque não existem caixas, carneiros ou átomos iguais. E no que diz respeito a este sistema, ele estaria tão correto em sua afirmação quanto nós na nossa. Certamente que um sistema de quantificação intensiva seria mais pobre em seu desempenho de muitas operações de, isto é, de uma forma mais envolvida, do que a matemática numérica. $O$ fato de que esta última se desenvolveu muito além do que a capacidade de estimar a quantidade intensiva diz já dela ser a mais 'prática'. Mas ainda assim é, e permanece, apenas um órgão, uma 'hipótese de trabalho inata', evolutivamente adquirida, que basicamente é se adapta aproximadamente aos dados da coisa-em-si.

Se um biólogo tenta apreender a relação da estrutura hereditária da plasticidade regulada de tudo quanto é orgânico, ele chega a uma lei universal que se mantém tanto para as estruturas físicas como para as intelectuais, e tão válidas para o protoplasma plástico e os elementos esqueletais de um protozoário como para as formas categóricas do pensamento e da criatividade plástica da mente humana. Desde as suas origens mais simples no domínio dos protozoários, a estrutura sólida é tanto uma condição para qualquer evolução superior como é para a plasticidade orgânica. Neste sentido, a estrutura sólida é uma propriedade tão indispensável e consistente da matéria viva quanto a sua liberdade plástica. Contudo, toda a estrutura sólida, embora indispensável como suporte para um sistema orgânico, leva consigo um efeito colateral indesejado: contribui para a rigidez e tira [assim] um certo grau de liberdade do sistema. Todo o alistamento de uma estrutura mecânica significa, num certo sentido, vincular-se. Von Uexkuell 7 disse muito bem: "A amiba é menos uma máquina do que um cavalo" ${ }^{\prime}$, pensando principalmente nas propriedades físicas. Nietzsche expressou poeticamente a mesma relação entre estrutura e plasticidade no pensamento humano: "Um pensamento - agora ainda lava líquida incandescente, mas toda a lava constrói um castelo à sua volta. Todo o pensamento finalmente se esmaga com 'leis"' . Esta comparação com uma estrutura cristalizando-se a partir de um estado líquido vai bem mais fundo do que Nietzsche supunha: Não é totalmente impossível que tudo o que se torna sólido, no psíquico-intelectual bem como no físico, esteja ligado a uma transição de um estado líquido de certas partes de plasma para um estado sólido.

Mas a comparação de Nietzsche e a afirmação de Uexkuell deixaram algo de lado. O cavalo é um animal que é mais elevado do que uma amiba não apesar, mas em maior medida pelo

\footnotetext{
7 N. do. T.: Jakob von Uexküll (1864-1944), biólogo alemão, famoso por ter proposto a noção de Umwelt.

8 N. do T.: Citação retirada do livro Umwelt und Innenwelt der Tiere (1909), onde se lê" so muß man sagen: die Amöbe ist weniger Maschine als das Pferd" (UEXKÜLL, 1909, p. 26).

9 N. do T.: Citação retirada de uma antologia de poemas de Nietzsche. Mais precisamente, da seção Aus dem Umkreis der DionysosDithyramben (1882-1888), número 19, onde se lê: "Ein Gedanke, / jetzt noch heiß-flüssig, Lava: / aber jede Lava baut / um sich selbst eine Burg, / jeder Gedanke erdrūckt / sich zuletzt mit 'Gesetzen'"' (NIETZSCHE, 1993, p. 109).
} 
seu ser mais rico em estruturas sólidas diferenciadas. Os organismos com tão poucas estruturas quanto sejam possível devem permanecer amibas, gostem ou não, pois sem estruturas sólidas, toda a organização superior é inconcebível. Poder-se-ia simbolizar organismos com um máximo de estruturas fixas altamente diferenciadas, como as lagostas, criaturas rigidamente protegidas que apenas se podem mover em certas juntas com graus precisamente permitidos de liberdade ou como as carruagens de um trem que apenas se podem mover ao longo de uma linha prescrita, tendo poucos pontos de comutação. Para cada ser vivo, uma maior diferenciação mental e física é sempre um compromisso entre estes dois extremos, nenhum representando a mais alta expressão das possibilidades da criação orgânica. Sempre e em toda a parte, a diferenciação de um nível mais elevado de estrutura mecânica tem a tendência perigosa de aprisionar a mente, da qual era serva há momentos, e de impedir a sua posterior evolução. $O$ duro exoesqueleto dos artrópodes é uma tal obstrução na evolução como também o são os movimentos instintivos de muitos organismos superiores e a maquinaria industrial do homem.

$\mathrm{Na}$ verdade, cada sistema de pensamento que se compromete com um 'absoluto' não-plástico tem este mesmo efeito aprisionador. No momento em que tal sistema esteja terminado, quando tem discípulos que acreditam na sua perfeição, é já 'falso'. Apenas no estado de vir a ser é o filósofo um ser humano no mais apropriado sentido da palavra. Lembro-me [aqui] de uma bela definição de homem que devemos ao pragmático Gehlen ${ }^{10}$, e que provavelmente é dada na sua formulação mais clara no livro Der Mensch ${ }^{11}[$ :] $O$ homem é definido como um ser permanentemente inacabado, permanentemente desadaptado e pobre em sua estrutura, mas continuamente aberto ao mundo, continuamente no estado de vir a ser.

Quando o pensador humano, seja ele o maior, terminou o seu sistema, ele tomou, de uma maneira fundamental, as características de uma lagosta ou de uma carruagem de um trem. Não obstante o quão engenhosamente possam os seus discípulos manipular os graus prescritos e permitidos de liberdade da sua armadura de lagosta, o seu sistema apenas será uma bênção para o progresso do pensamento e conhecimento humanos quando ele encontra discípulos que desmontem tal sistema e, usando novos, não'embutidos', graus de liberdade, transformam as suas peças numa nova construção. Se, contudo, um sistema de pensamento está tão bem montado que por um longo período de tempo não aparece alguém que tenha o poder e a coragem de o partir aos pedaços, tal sistema pode obstruir o progresso ao longo de séculos: "Ali está a pedra, tem de se deixá-la estar lá, e todos mancam, na sua muleta, para a pedra do diabo, para a ponte do diabo"12 (GOETHE, Fausto).

E exatamente como um sistema de pensamento criado por um ser humano individual escraviza o seu criador, também o fazem as formas de pensamento a priori supraindividuais desenvolvidas evolutivamente. Elas, também, são tidas como absolutas! A máquina cujo sentido preservador-da-espécie era originalmente o de quantificar coisas externas reais, a máquina que foi criada para 'contar carneiros', de repente pretende ser absoluta e avança com uma admirável falta de fricção e contradição internas, mas apenas enquanto corre vazia, contando as suas próprias pás. Se se deixar uma draga, um motor, uma serra, uma teoria, ou uma função de pensamento a priori correr vazia desta forma, então a sua função procede ipso facto $^{13}$ sem fricção,

\footnotetext{
${ }^{10}$ N. do T.: Arnold Gehlen (1904-1976), filósofo, sociólogo e antropólogo alemão.

${ }^{11}$ N. do T.: Der Mensch. Seine Natur und seine Stellung in der Welt (1940).

${ }^{12}$ N. do T.: Aqui Lorenz está a parafrasear a obra de Goethe. No original está: "Da liegt der Stein man muß ihn liegenlassen, und jeder hinkt an seiner Glaubenskrücke zum Teufelsstein, zur Teufelsbrücke!" (1941, p. 108). Já em Goethe, lê-se: "Da liegt der Fels, man muß ihn liegen lassen, / Zu Schanden haben wir uns schon gedacht. - / Das treugemeine Volk allein begreift / Und läßt sich im Begriff nicht stören;/Ihm ist die Weisheit längst gereift:/Ein Wunderist's, der Satan kommtzu Ehren./Mein Wandrer hinkt an seiner Glaubenskrücke, / Zum Teufelsstein, zur Teufelsbrücke" (1832, p. 254).

${ }^{13}$ Latim para pelo próprio fato.
} 
calor ou ruído detectáveis; pois as partes em tal sistema não contradizem, claro, umas com as outras e, por isso, encaixam-se conjuntamente de forma inteligível e bem afinada. Quando vazias, elas são realmente 'absolutas' [-] mas absolutamente vazias. Só quando se espera que o sistema funcione, ou seja, que obtenha algo em relação ao mundo externo no qual o sentido real e preservador-da-espécie de toda a sua existência realmente consiste, então a coisa começa a gemer e a se partir: quando as pás da draga escavam o solo, os dentes da serra rasgam a madeira, as assunções da teoria penetram o material dos fatos empíricos que tem de ser classificado, então aí surgem ruídos colaterais indesejados que resultam da inevitável imperfeição de todo o sistema naturalmente desenvolvido: e assim existem outros sistemas para o cientista natura ${ }^{14}$. Mas estes ruídos são apenas o que realmente representa o lidar do sistema com o mundo externo real. Neste sentido, [os ruídos] são a porta através da qual a coisa-em-si se mostra no nosso mundo dos fenômenos, a porta através da qual a estrada que leva a ainda mais conhecimento continua a conduzir. Eles, e não o zum-zum vazio sem resistência do aparato, são a 'realidade'. Eles são, na verdade, o que temos de colocar sob a lupa se quisermos ganhar conhecimento para lá destas imperfeições. Os ruídos colaterais têm de ser considerados metodicamente se é para aperfeiçoar a máquina. Os fundamentos da razão pura são tão imperfeitos e pés-no-chão quanto a serra, mas também tão reais.

A nossa hipótese de trabalho deve ser lida da seguinte forma: Tudo é uma hipótese de trabalho. Isto é verdade não apenas para as leis naturais que descobrimos através da abstração individual a posteriori a partir dos fatos da nossa experiência, mas também para as leis da razão pura. A faculdade do entendimento não constitui em si uma explicação dos fenômenos, mas o fato de que projeta para nós os fenômenos numa forma que seja utilizável, na prática, no ecrã de projeção da nossa experimentação deve-se à sua formulação de hipótese de trabalho, desenvolvida e testada ao longo de milhões de anos. Santayana ${ }^{15}$ diz: "A fé no intelecto é apenas fé que se justificou a si mesma pelo fruto pelo qual nasceu. Mas aquele que se aferra para sempre à forma da fé é um Dom Quixote, chocalhando com uma armadura antiquada. Eu sou um materialista convicto no que diz respeito à filosofia natural, mas não afirmo saber o que é a matéria. Estou à espera que os homens da ciência mo digam"16.

A nossa visão de que todo o pensamento humano é apenas uma hipótese de trabalho não deve ser interpretada como diminuindo o valor do conhecimento obtido pela humanidade. É verdade que nós estamos prontos, a qualquer momento, para atirar fora as nossas teorias favoritas quando novos fatos o demandam. Mas mesmo que nada seja 'absolutamente verdade', cada novo pedaço de conhecimento, cada nova verdade, é todavia um passo em frente numa direção bem definida e definível: o absolutamente existente é apreendido a partir de um novo, e até este ponto, aspeto desconhecido; está coberto numa nova característica. Para nós, a hipótese de trabalho é verdade, o que abre o caminho para o próximo passo no conhecimento ou que não obstrui a passagem. A ciência humana tem de agir como um andaime para alcançar a maior altura possível, sem que a sua extensão absoluta seja previsível no começo da construção. No momento em que tal construção fica comprometida com um pilar de apoio, este corresponde

\footnotetext{
${ }^{14}$ Em itálico no original.

${ }^{15}$ N. do T.: Jorge Agustín Nicolás Ruiz de Santayana y Borrás (1863-1952), mais conhecido como George Santayana, filósofo e escritor hispano-americano.

${ }^{16} \mathrm{~N}$. do T.: A passagem, infelizmente, não se encontra referenciada e pesquisas pelos termos exatos não conduziram a qualquer obra de Santayana. Contudo, há nela fragmentos que parecem retirados do livro The The Life of Reason: The Phases of Human Progress (1905). A saber: "Faith would have meant faith in the intellect, a faith naturally expressing man's practical and ideal nature, and the only faith yet sanctioned by its fruits" $(2011$, p. 60) e "A great imaginative apathy has fallen on the mind. One-half the learned world is amused in tinkering obsolete armour, as Don Quixote did his helmet; deputing it, after a series of catastrophes, to be at last sound and invulnerable" (2011, p. 5). Estaria Lorenz a parafrasear de memória?
} 
apenas a um edifício de uma certa forma e tamanho. Uma vez que estas [formas e tamanho] sejam alcançadas e o edifício tenha de continuar, o pilar de apoio tem de ser demolido e reconstruído, um processo que se pode tornar tão mais perigoso para toda a estrutura quão mais profundo esteja assente na sua fundação aquilo que tenha de ser reconstruído. Já que é uma propriedade constituinte de toda a verdadeira ciência que a sua estrutura deva continuar a crescer sem limites, tudo o que é mecanicamente sistemático, tudo o que corresponde a estruturas sólidas e a andaimes, tem sempre de ser algo provisório, alterável a qualquer ponto. A tendência para proteger o futuro do próprio edifício, ao declará-lo absoluto, conduz ao oposto daquilo que se pretendia: Que essa 'verdade', que é dogmaticamente acreditada, cedo ou tarde leva a uma revolução na qual o conteúdo de verdade e o valor da velha teoria são facilmente demolidos e esquecidos, juntamente com as obstruções obsoletas ao progresso. As pesadas perdas culturais que podem acompanhar as revoluções são casos especiais deste fenômeno. $\mathrm{O}$ caráter de todas as verdades como hipóteses de trabalho deve sempre ser tido em consideração por forma a impedir a necessidade de demolir a estrutura estabelecida, e por forma a salvaguardar as verdades 'estabelecidas', esse eterno valor que potencialmente merecem.

A nossa concepção de que as formas de pensamento e intuição a priori devem ser entendidas como qualquer outra adaptação orgânica traz [já] consigo o fato de que elas são para nós 'hipóteses de trabalho herdadas', assim por dizer, cujo conteúdo de verdade está relacionado com o absolutamente existente da mesma forma que as nossas hipóteses de trabalho cotidianas já deram provas de serem esplendidamente adequadas em lidar com o mundo externo. Esta concepção, é verdade, destrói a nossa fé na verdade absoluta de qualquer tese a priori necessária para o pensamento. Por outro lado, dá a convicção de que algo realmente'corresponde adequadamente' a cada fenômeno no nosso mundo. Mesmo o mais pequeno detalhe do mundo dos fenômenos 'espelhado' em nós pela hipótese de trabalho inata das nossas formas de intuição e pensamento é, de fato, pré-formada para o fenômeno que reproduz, tendo uma relação correspondendo àquela que existe entre as estruturas orgânicas e o mundo externo em geral (e.g., a analogia da barbatana do peixe e do casco do cavalo, mencionada acima). É verdade que o a priori é apenas uma caixa cuja forma corresponde despretensiosamente àquilo da atualidade ${ }^{17}$ que tem de ser retratado. Esta caixa, contudo, é acessível à nossa investigação mesmo que não compreendamos a coisa-em-si exceto através da própria caixa. Mas o acesso às leis da caixa, i.e., do instrumento, torna a coisa-em-si relativamente compreensível.

Agora o que estamos a planejar fazer num trabalho de pesquisa empírica paciente é uma investigação do 'a priori', da hipótese de trabalho 'inata' presente nos organismos sub-humanos. Isto inclui espécies que alcançaram uma correspondência às propriedades da coisa-em-si menos detalhada do que a do humano. Com toda a sua incrível precisão de objetivo, os esquematismos inatos dos animais são ainda muito mais simples, uma tela mais grosseira, do que os do homem, de tal forma que os limites dos seus sucessos ainda ficam aquém naquele que é o domínio mensurável do nosso próprio aparato receptivo. Tomemos como analogia o domínio que pode ser resolvido com a lente de um microscópio: A finura da mais pequena estrutura do objeto ainda visível com [o microscópio] é dependente da relação do ângulo da abertura e comprimento focal, a chamada 'abertura numérica'. O primeiro espectro de difração que é lançado pela grade estrutural ainda deve cair na lente frontal para que a grade seja vista como tal. Se isso não mais for o caso, não se vê a estrutura; ao invés, o objeto aparece como uma superfície suave e, estranhamente que seja, castanha.

\footnotetext{
${ }^{17}$ N. do T.: Wirklichkeit, no original.
} 
Agora suponhamos que eu apenas tivesse um microscópio. Então eu diria que as estruturas são apenas 'concebíveis' até uma determinada finura, e que as mais finas não existem. Além do mais, embora eu tivesse de admitir que existem objetos castanhos, eu não teria razão para assumir que esta cor tivesse a mínima relação com as estruturas visíveis. Contudo, se também se soubesse de lentes com menos resolução cujos instrumentos registrassem estruturas como 'castanhas', então ter-se-ia de se ser muito cético em relação ao nosso instrumento registrar castanho (a não ser que me tivesse tornado megalomaníaco e pronunciado o meu próprio aparato receptivo como absoluto, pela simples razão de que era meu). Se se fosse mais modesto, porém, tirar-se-ia a conclusão apropriada a partir da comparação dos limites de obtenção e do fato de que os vários instrumentos registravam castanho. A conclusão é a de que lentes ainda mais poderosas têm limites quanto à finura da estrutura que podem revelar, tal como acontece com aparatos mais simples. Duma forma similarmente metódica, pode-se aprender bastante das limitações funcionais que têm todos os vários aparatos para organizar a imagem do universo. A lição assim aprendida providencia uma perspectiva crítica importante para julgar os limites de obtenção do mais alto aparato existente, que hoje em dia não pode ser investigado da torre de observação de um que ainda lhe fique mais alto.

Observando-o de uma perspectiva fisiológica, é auto evidente que o nosso aparato neural para organizar a imagem do mundo é basicamente como uma tela de reprodução de fotos, que não pode reproduzir quaisquer pontos mais finos da coisa-em-si do que aqueles que correspondem aos elementos numericamente finitos da tela. Tal como o grão do negativo fotográfico não permite uma imagem ampliada sem limites, também existem limitações na imagem do universo traçada pelos nossos órgãos dos sentidos e pelo nosso aparato cognitivo. Estes também não permitem uma 'ampliação' sem limites, qualquer visão ilimitada dos detalhes, por mais autoevidente e real que a imagem possa parecer numa análise superficial. Onde a imagem física do universo formada pelo homem avançou até ao nível atômico, surgem aí imprecisões na coordenação entre as 'necessidades do pensamento' a priori e o que é empiricamente real. É como se a "medida de todas as coisas" 18 fosse simplesmente demasiado grosseira e extremamente aproximada para essas esferas mais finas de medição, e apenas concordaria em geral, e a um nível probabilístico-estatístico, com aquilo que tem de ser compreendido da coisa-em-si. Isto é cada vez mais verdadeiro para a física atômica, cujas ideias inteiramente impalpáveis não mais podem ser experimentadas diretamente. Pois nós apenas podemos 'detalhar como experiência' duma forma diretamente experienciável (para aplicar a própria expressão de Kant a este fato fisiológico) aquilo que pode ser escrito no 'teclado' grosseiramente simplificado do nosso sistema nervoso central. Mas em diferentes organismos, este teclado pode ser diferenciado duma forma mais ou menos complexa. Para representá-lo na analogia com a tela de impressão de fotografias, a melhor fotografia que pode ser reproduzida por um aparato de um determinado grau de finura corresponde àquelas representações encontradas em bordados de ponto cruz, que desenham animais e flores com contornos redondos a partir de pequenos elementos retangulares. A propriedade de'ser composta de quadrados' não pertence de todo à coisa-em-si representada, mas deve-se à peculiaridade do aparato de imagem, uma peculiaridade que pode ser vista como uma limitação técnica inevitável. Limitações similares acompanham cada aparato para organizar a imagem do mundo, nem que não seja pelo fato de serem compostos de elementos celulares (como é o caso da visão). Ora, se se examinar metodicamente o que a

\footnotetext{
${ }^{18} \mathrm{~N}$. do T.: Embora não referenciada, isto é uma alusão à famosa frase de Protágoras, "O homem é a medida de todas as coisas". Ou, mais corretamente, "De todas as coisas a medida é o homem, das coisas que são, que o são, das coisas que não são, que não são" (FREEMAN, 1983, p. 125, tradução nossa).
} 
representação em ponto cruz permite dizer sobre a forma da coisa-em-si, a conclusão da precisão da afirmação depende da relação entre o tamanho da figura e o grão da tela. Se um quadrado está desalinhado com o contorno retilíneo do bordado, sabe-se que por detrás dele está uma projeção real da coisa representada, mas não se tem a certeza se preenche exatamente todo o quadrado da tela ou apenas a sua mais pequena parte. Esta questão apenas pode ser decidida com a ajuda da próxima tela mais fina. Mas por detrás de cada detalhe que até a tela mais grosseira reproduz existe, por certo, algo real, simplesmente porque doutra forma não teria sido registrada na respetiva unidade de tela. Mas nenhuma ferramenta está ao nosso dispor para determinar o que está por detrás do registro da unidade mais fina de tela, quer sobressaia muito ou pouco do contorno daquilo que é para ser representado no seu domínio. $A$ indiscernibilidade fundamental do último detalhe da coisa-em-si permanece. Nós estamos apenas convencidos de que todos os detalhes que o nosso aparato reproduz correspondem aos atributos reais da coisa-em-si. Fica-se cada vez mais convencido desta correlação inteiramente real e lícita entre o Real e o Aparente quanto maior for a preocupação com a comparação de aparatos para organizar a imagem do mundo de animais tão diferentes uns dos outros quanto possível. A continuidade da coisa-em-si, que emerge mais convincentemente de tais comparações, é completamente incompatível com a suposição de uma relação alógica, extrinsecamente determinada, entre a coisa-em-si e as suas aparências.

Tal pesquisa comparativa coloca-nos mais próximos de um mundo efetivo por detrás dos fenômenos, desde que consigamos mostrar que as diferentes formações a priori de relações possíveis (e, por isso, de possíveis experiências) das diferentes espécies tornam experienciável a mesma legitimidade de existentes reais e conduz ao seu controlo duma forma preservadora-da-espécie. Essas adaptações diferentes a uma e a mesma legitimidade reforça a nossa crença na sua realidade, da mesma maneira que a crença de um juiz na realidade de um evento é reforçada por várias testemunhas mutuamente independentes que, dando descrições [do ocorrido], estão de acordo, embora [suas descrições] não sejam idênticas. Os organismos que estão num nível mental muito inferior do que o de um homem digladiam-se de forma bastante evidente com os mesmos dados que são tornados experienciáveis no nosso mundo das formas de percepção do espaço e tempo, e através de feitos bem diferentes e muito mais simples, que estão acessíveis à análise científica. Mesmo se as formas humanas a priori da percepção e pensamento permanecem inacessíveis por muito tempo à análise causal, nós, como cientistas naturais, devemos contudo desistir de explicar a existência do a priori (ou da razão pura em geral) através de um princípio estranho à natureza. Devemos, pelo contrário, olhar quaisquer tentativas explanatórias como uma divisão completamente arbitrária e dogmática entre o racionalmente compreensível e o incognoscível, uma divisão que causou um sério dano ao obstruir a pesquisa, como as proibições aos pensadores vitalistas.

O método a ser usado pode ser explicado, através da analogia do microscópio, como uma ciência de aparatos. Basicamente, apenas podemos compreender os precursores inferiores das nossas formas de percepção e pensamento. Apenas onde puderem ser identificadas as leis representadas através destes órgãos primitivos com aquelas representadas no nosso próprio aparato, podemos nós clarificar as propriedades do a priori humano, usando o mais primitivo como ponto de partida. Desta forma, podemos tirar conclusões sobre a continuidade do mundo por detrás dos fenômenos. Uma tal empreitada tem bastante sucesso quando comparada com a teoria das formas de percepção a priori do espaço e a categoria da causalidade. Um grande número de animais não compreende a estruturalização 'espacial' do mundo da mesma forma que nós. Podemos, contudo, ter uma ideia aproximada de como o 'espacial' aparenta no retrato do mundo de tais organismos porque, para além da nossa apreensão espacial, também possu- 
ímos a capacidade de lidar da maneira deles com problemas espaciais. A maioria dos répteis, pássaros e mamíferos inferiores não lidam com os problemas espaciais como nós fazemos através de uma inspeção clara dos dados. Ao invés, os problemas espaciais são aprendidos por repetição. Por exemplo, um musaranho aquático, quando colocado num novo ambiente, gradualmente aprende, por repetição, todos os caminhos possíveis através de lentamente rastejar à volta, guiado constantemente pelo farejar e sentir com os bigodes duma forma [semelhante] à de como uma criança aprende a tocar peças de piano por repetição. Na trabalhosa sequência fragmentada dos movimentos dos membros, estas pequenas extensões tornam-se 'movimentos conhecidos', seguidos de uma suave ligação destas partes. E estes movimentos, acabando mais suaves e constantes ao se tornarem cinesteticamente entranhados, estendem-se cada vez mais longe e finalmente fluem em conjunto num todo inseparável que, correndo de forma veloz e suave, não mais tem qualquer semelhança com os movimentos originais de busca. Estas sequências de movimento, tão laboriosamente adquiridas, e correndo tão extraordinariamente rápidas e suaves, não seguem pelo 'caminho mais curto'. Pelo contrário, o acaso determina qual o padrão espacial que tal caminho toma. Chega mesmo a acontecer que o caminho tortuoso se cruza consigo mesmo, sem que o animal necessariamente se dê conta que o trajeto pode ser encurtado ao cortar esta parte supérflua do caminho ${ }^{19}$.

Para um animal, como o musaranho aquático, que ganha domínio sobre o seu espaço vital quase que exclusivamente por aprendizado de caminho, a tese de que a linha reta é a conexão mais curta entre dois pontos não é de todo válida. Se ele quisesse seguir numa linha reta (algo que está basicamente dentro das suas possibilidades), teria de constantemente se aproximar do seu objetivo através de farejar, sentir pelos bigodes e fazendo uso dos seus olhos, que não são muito eficazes. Nesse processo, ele usaria mais tempo e energia do que seguindo o caminho que conhecia por repetição. Se dois pontos que neste caminho ficassem bastante distantes estivessem espacialmente próximos, o animal não o saberia. Até mesmo um ser humano pode se comportar desta maneira [-] por exemplo, numa cidade estranha. É verdade, todavia, que sob essas circunstâncias, nós humanos acabamos, tarde ou cedo, por conseguir uma perspectiva espacial que nos abre a possibilidade de um atalho por meio de uma reta. $\mathrm{A}$ ratazana do esgoto, que está num nível mental muito superior do que o do musaranho, da mesma forma depressa encontra atalhos. O ganso poderia, como vimos [na nota 19], conseguir

\footnotetext{
${ }^{19}$ Ratos e outros mamíferos que estão num nível mental superior ao de um musaranho aquático dão-se conta imediatamente de tais possibilidades de um atalho. Eu presenciei um caso interessante com um ganso-bravo no qual a possibilidade de um atalho na aprendizagem do caminho foi, sem dúvida, notada, mas não usada. Quando [ainda] um gansinho, esta ave tinha aprendido um caminho que o conduzia através de uma porta da nossa casa, subindo dois vãos de uma larga escada até ao meu quarto, onde o ganso costumava passar a noite. De manhã, ele costumava sair voando pela janela. Quando estava a aprender o caminho, o jovem ganso-bravo, primeiro que tudo, corria para uma grande janela na ainda estranha escada, passando pelo degrau mais baixo. Muitos pássaros, quando estão assustados, buscam a luz, e então este ganso, também, decidiu sair pela janela e vir para o patamar para o qual eu queria conduzi-lo somente depois dele se ter acalmado um pouco. Este atalho para a janela permaneceu de uma vez por todas uma parte indispensável do caminho aprendido que o ganso tinha de percorrer no seu trajeto para onde costumava dormir. Este atalho íngreme para a janela e voltando dela dava um efeito mecânico, quase como uma cerimônia executada por hábito, porque a sua motivação original (ansiedade e, por isso, fugindo da escuridão) não mais estava presente. No decurso da aprendizagem do caminho deste ganso, que levou quase dois anos, o atalho tornou-se gradualmente mais inclinado[;] ou seja, a linha, que originalmente ia quase tão longe quanto indo e voltando da janela, tinha agora inclinado para baixo, num ângulo agudo, pelo qual o ganso se tinha desviado do seu trajeto em direção à janela e subindo o último degrau na extremidade que estava de frente para a janela. Esta nivelação do desnecessário o teria provavelmente levado a descobrir o caminho mais curto com mais dois anos e não teve qualquer relação com um vislumbre (insight) seu; muito embora o hábito tivesse prevalência sobre o vislumbre ou chegado mesmo a impedi-lo. Numa tardinha aconteceu o seguinte[:] Eu me tinha esquecido de deixar entrar o ganso na casa e, quando finalmente me lembrei, ele estava à espera impacientemente no degrau da porta, passando a correr por mim e - para minha grande surpresa - pela primeira vez seguiu pelo caminho mais curto subindo as escadas. Mas ia já no terceiro degrau quando parou, esticou o seu pescoço, soltou o seu grito de aviso, voltou para trás, desceu novamente os três degraus, fez apressadamente e'formalmente' o desvio para a janela e então subiu calmamente as escadas da forma usual. Aqui obviamente a possibilidade de uma solução através de um vislumbre foi bloqueada apenas pela existência daquele aprendizado por treino!
} 
a mesma coisa, mas não o faz por razões religiosas ${ }^{20}$, como é o caso; é impedido por essa inibição peculiar que tanto amarra os povos primitivos ao hábito. O significado biológico deste aferro rígido à 'tradição' é facilmente compreensível: é sempre mais aconselhável, para um organismo que não tem à sua disposição o levantamento espacial-temporal-causal sobre uma certa situação, persistir rigidamente no seu comportamento que se provou bem-sucedido e livre de perigos. $O$ assim chamado pensamento mágico, não apenas presente nos povos primitivos, está bem próximo deste fenômeno. Basta pensar no bem conhecido [gesto de] 'bater na madeira'. O motivo para [se dizer] "afinal, não se sabe o que acontecerá se se deixar de o fazer" é muito claro.

Para uma criatura verdadeiramente cinestésica, tal como o musaranho aquático, é literalmente impossível, pelo menos no que diz respeito ao pensar, encontrar um atalho. Talvez aprenda quando forçado pelas circunstâncias externas, mas, de novo, apenas aprendendo por repetição, desta vez um novo caminho. Doutra forma, existe uma parede impenetrável para o musaranho aquático entre duas voltas do seu caminho, mesmo quando estas quase se tocam. Quantas mais dessas possibilidades de solução, em princípio igualmente simples, nós humanos podemos negligenciar com igual cegueira em nossas lutas com os problemas do dia-a-dia! Este pensamento se impõe com uma força persuasiva sobre qualquer um que, em suas associações diárias com animais, tenha descoberto muitas das suas características humanas e, ao mesmo tempo, os seus limites fixos daquilo que podem alcançar. Nada pode ser mais apto para fazer com que o cientista duvide do seu próprio caráter como-que-divino e para lhe inculcar uma modéstia muito benéfica.

Do ponto de vista psicológico, o domínio espacial do musaranho aquático resulta de uma sequência de reflexos condicionados e de movimentos cinestesicamente entranhados. Ele reage às marcas diretivas do seu caminho com reflexos condicionados que são menos do que um direcionamento do que um controlo para determinar se ainda está no caminho certo, pois o movimento cinestésico sabido por repetição é tão preciso e exato que o processo se dá quase sem um direcionamento ótico ou tátil, tal como acontece com um bom pianista que quase que nem precisa de olhar quer para a partitura quer para as teclas. Esta formação sequencial de reflexos condicionados e de movimentos decorados não é de todo unicamente espacial, mas também uma formação espaciotemporal[:] apenas se pode produzir numa direção. Correr o trajeto ao contrário requer um treino completamente distinto. Correr na direção contrária os caminhos aprendidos por repetição é quase tão impossível como recitar o alfabeto fora de sequência. Se se interrompe o animal a correr ao longo do seu trajeto treinado, tirando um obstáculo que tinha de ser pulado, ele fica desorientado e tenta reconectar a sequência de elos entranhados num ponto anterior. Por essa razão, volta atrás a fazer buscas até que se reoriente pelos sinais do seu caminho e tenta de novo, tal como uma pequena garota que tenha sido interrompida enquanto recitava o seu poema.

Uma relação muito similar àquela que encontramos entre a disposição para aprender caminhos por repetição e a forma humana de percepção de espaço existe entre a disposição a desenvolver reflexos (associações) condicionados e a categoria humana da causalidade. $\mathrm{O}$ organismo aprende que um certo estímulo, por exemplo, a aparência do guardador, precede sempre um evento biologicamente relevante, digamos, comer; [este organismo] 'associa' estes dois eventos e trata o primeiro como sinal para a ocorrência do segundo ao encetar reações preparatórias no início do primeiro estímulo (e.g., o reflexo de salivação investigado por Pavlov).

\footnotetext{
${ }^{20}$ N. do T.: A palavra não está italicizada no original. A opção pretende enfatizar que o uso desta palavra é aqui alegórico.
} 
Esta conexão de uma experiência com o post hoc ${ }^{21}$ que regularmente lhe segue está totalmente desconectada com o pensamento causal. Deve ser lembrado que, por exemplo, a secreção dos rins, um processo completamente inconsciente, pode ser adestrado a [ponto de] se tornar um reflexo condicionado! A razão pela qual o post hoc era ainda equacionado e confundido com o propter hoc ${ }^{22}$ é que a disposição para a associação e pensamento causal efetivamente alcançava biologicamente a mesma coisa; eles são, assim por dizer, órgãos para lidar com o dado real.

Este dado é, sem qualquer dúvida, a legitimidade natural contida numa tese maior da física. O 'reflexo condicionado' surge quando um certo estímulo exterior, sem sentido para o organismo como tal, é várias vezes seguido por outro, biologicamente significativo, ou seja, um que leve a uma reação. $O$ animal de agora em diante se comporta 'como se' o primeiro estímulo fosse um sinal seguro precedendo o evento biologicamente significativo que se deve esperar. Este comportamento obviamente apenas tem um significado preservador-da-espécie se, no contexto do real, existir, entre estímulos, uma conexão entre o primeiro, o 'condicionado', e o segundo, o 'incondicionado'. Uma sequência temporal lícita de eventos diferentes ocorre regularmente na natureza apenas quando uma certa quantidade de energia aparece, sequencialmente, em diferentes formas fenomenais através da transformação da força. Esta conexão, por si só, significa 'conexão causal'. O reflexo condicionado 'advoga a hipótese' que dois estímulos, ocorrendo várias vezes numa certa sequência, são formas fenomenais da mesma quantidade de energia. Se esta suposição fosse falsa e a sequência repetida condicionando a associação dos estímulos fosse apenas puramente acidental, num 'post hoc' que provavelmente nunca mais se repetisse, então o desenvolvimento da reação condicionada seria uma falha disteleológica de consecução da parte da disposição que é geralmente e, probabilisticamente, significativa [; isto] no sentido de ser preservadora-da-espécie.

Uma vez que desconhecemos as suas fundações fisiológicas, apenas podemos examinar a categoria da causalidade através da epistemologia crítica. Na sua função biológica, é um órgão para compreender a mesma licitude natural direcionada à disposição para adquirir reflexos condicionados. Não podemos definir de qualquer outra forma um conceito de causa e efeito do que através de determinar que o efeito recebe energia a partir da causa, seja por que maneira for. A essência do 'propter hoc', a única que o distingue qualitativamente de um 'post hoc uniforme', assenta no fato que a causa e efeito são elos sucessivos na sequência infinita de formas fenomenais que a energia assume ao longo da sua perpétua existência.

No caso de uma categoria da causalidade, a tentativa de explicá-la como uma abstração secundária a partir da experiência precedente (no sentido de Wundt) é iluminadora. Caso se tente [tal explicação], chega-se sempre à definição de um 'post hoc regular', mas nunca à qualidade altamente específica que reside a priori em todos os usos razoáveis do 'porquê', e do 'porque' de até mesmo uma pequena criança. Não se pode esperar que uma criança tenha a capacidade de compreender abstratamente um fato que não foi descrito de um forma objetiva, i.e., puramente física, senão em 1842, por J. R. Mayer. Joule, numa palestra dada em 1847 ( $D a$ Matéria, Força Viva e Calor, Londres, 1884, p. 265) declarou, duma forma surpreendentemente simples, que é'absurdo' assumir que uma força pudesse ser destruída sem que de alguma forma restaurasse alguma coisa equivalente. $O$ grande físico toma assim, de forma bastante ingênua, o ponto de vista da epistemologia crítica. Seria uma questão bem interessante, do ponto de vista da história das ideias, se, na sua descoberta do equivalente do calor, ele partiu da 'impensabilidade' a priori da destruição e criação da energia, como aparenta que sim, [pelo menos] a

\footnotetext{
${ }^{21}$ N. do T.: Latim para depois disso.

22 N. do T.: Latim para por causa disso.
} 
julgar pela sua afirmação [parafraseada] acima. Não encaixa, no nosso conceito de causa e efeito, que a categoria a priori da causalidade se baseie de fato em nada mais do que na inevitável sequência de dois eventos, e que se pode dar que o evento ocorrendo mais tarde no tempo não retire a sua energia da que lhe precede, mas que ambas são sequências paralelas mutuamente independentes duma sequência causal ramificada. Pode-se dar o caso que um evento regularmente tem dois efeitos, dos quais um ocorre mais depressa que outro, assim sempre o precedendo na experiência. Deste modo, o relâmpago segue-se [sempre] mais rapidamente à descarga elétrica do que o trovão. Contudo, o fenômeno ótico não é de todo a causa do acústico! Talvez se possa objetar aqui que esta consideração é [mera] minúcia, e para muitas pessoas ingênuas o relâmpago é ainda a causa do trovão. Mas a minúcia liberta-nos de uma concepção primitiva e faz-nos subir um degrau mais próximo da verdadeira conexão das coisas. A humanidade hoje vive pela função da categoria inata da causalidade.

Vamos agora examinar metodologicamente os feitos funcionalmente análogos dos animais a partir da torre de observação superior da forma humana da percepção do espaço e da categoria da causalidade; primeiro, a disposição para o aprendizado cinestésico de caminhos por repetição e, depois, a disposição para a associação cega de eventos sequenciais. É 'verdade' o que o musaranho aquático 'sabe' sobre o espacial? No caso do musaranho aquático, o aprendizado cria um "ordo et conne[x]io idearum ${ }^{23 ",}$ também visível na nossa imagem do universo: nomeadamente, a condição de que lugares e partes locomotivas estão amarradas como num colar de pérolas. O esquema ordenado do musaranho aquático está inteiramente correto — tão longe quanto chega. Na nossa percepção, o colar de pérolas é também visível; a sequência das conexões é verdade. [O que acontece é que a]penas para nós existem (e são verdade) um imenso número de dados adicionais que faltam ao musaranho: por exemplo, a possibilidade de atalhar as voltas de um caminho. Também de um ponto de vista pragmático, a nossa percepção é verdade a um nível mais elevado do que a imagem do universo do animal.

Algo muito similar resulta quando comparamos a disposição para fazer associações com o nosso pensamento causal: aqui, também, a representação inferior, mais primitiva, do animal produz uma conexão entre eventos que igualmente existe em nossa forma de pensar: a relação temporal entre causa e efeito. A realidade mais profunda, essencial para o nosso pensamento causal, que a energia é recebida da causa pelo efeito não nos é dada pelo pensamento puramente associativo. Aqui então, [e] também, a forma inferior de pensamento corresponde $a$ priori e adequadamente à realidade de uma ordem superior, mas, de novo, apenas tanto quanto pode. Aqui, igualmente, a forma de pensamento humano é mais verdade do ponto de vista pragmático; pense-se em tudo o que alcança que não pode ser conseguido por associação pura! Como disse, todos nós [sobre]vivemos graças ao trabalho deste importante órgão, quase que tanto como pelo trabalho das nossas mãos.

Com toda a ênfase nestas diferenças de grau de correspondência entre a imagem do universo e a realidade, não nos devemos esquecer, por um momento que seja, que algo de real está a ser refletido mesmo nas 'telas' mais primitivas dos aparatos para organizar a imagem do universo. É importante enfatizá-lo, porque nós humanos também usamos tais aparatos, embora eles possam ser muito diferentes. O progresso na ciência tem sempre uma certa tendência para de-antropomorfizar a nossa imagem do universo, como Bertalanffy ${ }^{24}$ corretamente

\footnotetext{
${ }^{23}$ N. do T.: Latim para a ordem e conexão das ideias. A citação, não identificada no original, corresponde à frase "Ordo et connexio idearum idem est, ac ordo et connexio rerum" (1905, p. 32) da parte II, proposição VII da Ética, de Espinosa. A frase, no íntegra, diz: A ordem e a conexão das ideias é idêntica à ordem e conexão das coisas. No original de Lorenz estava "ordo et connectio idearum" (1941, p. 121). Daí a correção.

${ }^{24}$ N. do T.: Karl Ludwig von Bertalanffy (1901-1972), biólogo austríaco.
} 
apontou. A partir do fenômeno palpável e sensível da luz, o conceito de ondas impalpável, não passível de ser visualizado, foi produzido. A compreensão autoevidente da causalidade é substituída por considerações de probabilidade e cálculos aritméticos, etc. Pode-se de fato dizer que entre as nossas formas de percepção e categorias existem umas que são'mais antropomórficas' e umas que são 'menos antropomórficas'; ou que umas são mais especializadas e outras que são mais gerais. É indubitável que um ser racional que carecesse do sentido da visão poderia [ainda assim] compreender a teoria ondulatória da luz, embora não compreendendo a experiência perceptual específica de um humano. Ao olhar para lá das estruturas especificamente humanas, como se faz ao mais alto nível na ciência matemática, não se deve chegar à conclusão de que as representações menos antropomórficas alcançam um nível mais elevado de realidade, ou seja, que elas se acercam da coisa-em-si de forma mais aproximada do que a percepção mais ingênua. A reprodução ${ }^{25}$ mais primitiva tem uma relação com o absolutamente existente que é tão real quanto a da [reprodução] superior. Como tal, o aparato do animal para organizar a imagem do universo reproduz apenas um detalhe, e de uma forma puramente associativa, da realidade da transformação da energia de que um certo evento precede outro no tempo. Mas não se pode de forma alguma declarar que a afirmação 'uma causa precede um efeito' é menos verdade do que a afirmação de que um efeito surge de um fenômeno precedente através da transformação da energia. A progressão do simples para o mais diferenciado assenta no fato de que novas definições adicionais são acrescentadas àquelas que já existem. Se, em tal progressão de uma reprodução mais primitiva do universo para uma que lhe é superior, certos dados que são representados na primeira [reprodução] são negligenciadas na segunda, então trata-se apenas de uma questão de mudança de ponto de vista e não de uma maior aproximação ao absolutamente existente. As reações mais primitivas dos protozoários refletem um aspeto do mundo com o qual todos os organismos devem igualmente se relacionar, tanto quanto devem os cálculos de um Homo Sapiens que estudou física teórica. Mas não podemos determinar quão mais existe na realidade absoluta para além dos fatos e relações reproduzidas na nossa imagem do universo do que um musaranho aquático pode determinar que poderia atalhar muitos dos desvios do aprendizado tortuoso do seu trajeto.

Com relação à validade absoluta das nossas 'necessidades de pensamento', somos igualmente modestos: apenas acreditamos que, em alguns detalhes, estes correspondem mais [fielmente] ao absolutamente existente do que os do musaranho aquático. Acima de tudo, estamos conscientes do fato de que somos certamente tão cegos com relação a muitas coisas adicionais como o é o animal: que também nos faltam os órgãos receptivos para o infinitamente mais que é o real. As formas da percepção e categorias não são a mente, mas, ao invés, são ferramentas que a mente usa. Elas são estruturas inatas que, por um lado, dão-lhe suporte e que, por outro, compensam pela rigidez de tudo aquilo que é sólido[; como n]a importante concepção da ideia de liberdade de Kant, nomeadamente a de que o ser pensante é responsável perante a totalidade do universo, que sofre do mal de estar acorrentada às leis rigidamente mecânicas da razão pura. O a priori e as formas pré-moldadas do pensamento são apenas aquelas que não são, de todo, especificamente humanas como tal. Especificamente humano, contudo, é o impulso consciente de não ficar preso, de não se tornar um veículo sobre carris, mas, ao invés, de manter uma viçosa abertura ao se aproximar da realidade através de uma constante interação recíproca com o mundo.

Sendo biólogos, somos modestos quanto à posição do homem na totalidade da natureza, mas mais exigentes quanto àquilo que o futuro nos possa ainda trazer no que diz respeito

${ }^{25}$ N. do T.: A reprodução que Lorenz aqui refere é no sentido fotográfico, se assim podemos dizer. A representação de algo por derivação. 
ao conhecimento. Ao declarar o homem absoluto, ao afirmar que qualquer ser imaginável, até anjos, teriam de se limitar às leis do pensamento do Homo Sapiens, parece-nos de uma arrogância incompreensível. Em lugar da ilusão perdida da legitimidade única do homem, trocamos [tal ilusão] pela convicção de que, em sua abertura ao mundo, ele é basicamente capaz de superar a sua ciência e as formulações a priori do seu pensamento, e de elaborar e essencialmente perceber novas coisas que nunca antes existiram. Na medida em que continuar inspirado pela vontade de não estrangular cada novo pensamento pela [dura] capa de leis cristalizando-se à sua volta, tal como nas gotas de lava de Nietzsche, este desenvolvimento não encontrará no futuro próximo qualquer obstáculo essencial. Nisto assenta a nossa concepção de liberdade; é a grandiosidade e, pelo menos no nosso planeta, a singularidade provisória do nosso cérebro humano que, não obstante toda a sua gigantesca diferenciação e miniaturização, é um órgão cuja função possui uma mutabilidade quase que de um Proteu ${ }^{26}$, uma capacidade similar à da lava de se levantar contra as restrições funcionais impostas pela sua própria estrutura, ao ponto onde alcança uma flexibilidade ainda maior do que a de um protoplasma carecendo de estruturas sólidas.

Que diria Kant de tudo isto? Sentiria ele que a nossa interpretação naturalista da razão humana (para ele sobrenaturalmente dada) é uma profanação daquilo que é mais sagrado? (Tal acontece aos olhos da maioria dos neo-kantianos). Ou aceitaria ele, à luz das suas aproximações ocasionais ao pensamento evolutivo, a nossa concepção de que a natureza orgânica não é algo amoral ou abandonada por Deus, mas é basicamente 'sagrada' em suas façanhas evolutivas, especialmente nos seus sucessos superiores, a razão humana e a moralidade humana? Inclinamo-nos para acreditar que sim, porque acreditamos que a ciência jamais pode destruir uma deidade, mas apenas os ídolos com pés de barro feitos pelo homem. À pessoa que nos repreende acusando-nos de falta de respeito pela grandiosidade do nosso filósofo, contestamos ao citar o próprio Kant: “Se se começa com uma ideia fundamentada, mas não percebida e legada por outrem, pelo pensamento contínuo pode-se ter esperança em progredir mais do que o homem engenhoso a quem devemos a faísca desta luz"27. A descoberta do a priori é a luz que devemos a Kant e não é certamente arrogância nossa criticar a interpretação desta descoberta à luz de novos fatos (como fizemos ao criticar Kant no que diz respeito à origem das formas da percepção e categorias). Esta crítica não diminui mais o valor da descoberta do que o do descobridor. Para qualquer um que siga o princípio "Omnia naturalia sunt turpia"28, que persiste em ver uma profanação em nossa tentativa de olhar naturalisticamente a razão humana, de novo contestamos citando Kant: "Quando falamos da totalidade da natureza, temos de inevitavelmente concluir que existe uma regulação divina. Mas em cada fase da natureza" (uma vez que nenhuma nos é dada à simplesmente à partida no nosso mundo sensível) "temos a obrigação de procurar as causas subjacentes, tanto quanto se possa, e de seguir a sequência causal, contanto que tenha coerência, de acordo com as leis que por nós são conhecidas" 29 .

\footnotetext{
${ }^{26}$ N. do T.: Antiga divindade marítima grega, cuja principal característica era a sua constante capacidade de mudar de forma. Ao ser "quase que um Proteu", Lorenz procura sublinhar a virtualmente infinita capacidade de adaptação do nosso cérebro.

27 Prolegômenos a Qualquer Metafísica Futura que Possa Apresentar-se como Ciência (1783), introdução.

${ }^{28}$ N. do T.: Latim para tudo o que é natural é sujo, inversão de uma frase atribuída a Maurus Servius Honoratus comentando uma passagem de Virgílio nas Geórgicas: "turpis non est quia per naturam venit" (1819, p. 1975), não é sujo o que vem da natureza.

${ }^{29}$ Sobre os Vulcões na Lua (1785).
} 


\section{Referências bibliográficas}

FREEMAN, K. Ancilla to the Pre-Socratic Philosophers: A Complete Translation of the Fragments in Diels, Fragmente der Vorsokratiker. Reprint edition ed. Cambridge: Harvard University Press, 1983.

GOETHE, J. W. Von. Goethe's Werke. Stuttgart: J. G. Cotta'schen Buchhandlung, 1832.

LORENZ, K. Kant's Lehre vom Apriorischen im Lichte gegenwärtiger Biologie. Blätter für Deutsche Philosophie, 1941.v. 15, p. 94-125.

LORENZ, K. Kant's Doctrine of the A Priori in The Light of Contemporary Biology. In: RUSE, M. (Org.). Philosophy After Darwin: Classic and Contemporary Readings. [S.I.]: Princeton University Press, 2009, p. 231-247.

MARONIS, P.V. Opera Omnia Ex Editione Heyniana: Cum Notis et Interpretatione in Usum Delphini, Variis Lectionibus, Notis Variorum, Excursibus Heynianis, Recensu Editionum et Codicum et Indice Locupletissimo Accurate Recensita. London: A.J. Valpy, A. M., 1819. V. Volumen Quartum. NIETZSCHE, F. W. Gedichte. Stuttgart: Philipp Reclam jun. GmbH \& Co., 1993.

SANTAYANA, G. The life of reason: Introduction and Reason in Common Sense. Cambridge (Mass.): The MIT Press, 2011. V. VII, Book One.

SPINOZA, B. Ethica Ordine Geometrico Demonstrata. Haia: Martinus Nijhoff, 1905.

UEXKÜLL, J. Von. Umwelt und Innenwelt der Tiere. Berlin: Verlag von Julius Springer, 1909.

\section{Sobre o tradutor}

Henrique Capeleiro Maia

Mestrando em Filosofia pela Universidade Federal de Pernambuco. 